\title{
БЕЗОПАСНОСТЬ ПЛОТИН И СВЯЗАННЫЕ С НЕЙ ПРИРОДООХРАННЫЕ ВОПРОСЫ
}

\author{
Нониев И. К., к.т.н., ассои. профессор Грузинского Технического Университета, Тбилиси, Грузия \\ Шатакишвили Л. А., к.т.н., декан факультета Грузинского Технического Университета, \\ Тбилиси, Грузия \\ Хелидзе Г. К., д.т.н., профессор Грузинского Технического Университета, Тбилиси, Грузия \\ Мирихулава А. 3., магистр, докторант Грузинского Технического Университета, Тбилиси, Грузия
}

\section{DOI: https://doi.org/10.31435/rsglobal_conf/30012021/7382}

\begin{abstract}
Based on the factual data of the high-risk reservoir hydropower plants, in the paper presented a method that is proposed takes into account the potential energy of the accumulated water at an early stage of design and is properly assessed. The main factors affecting the scale of a possible catastrophe are the useful capacity of the reservoir and the height of the center of gravity of the reservoir from the bottom of the river bed at the dam section. Based on these data, the potential energy of the water mass was determined in case of a possible break of the dam. As an example, the results of calculations performed according to the proposed method for reservoirs of hydroelectric power plants in Georgia are given. With this in mind, it is possible to rank hydropower facilities and determine the frequency of inspections to reduce the risk of accidents and related negative environmental impacts. Among the reasons contributing to the occurrence of a possible emergency at the hydroelectric power station, the following were noted: untimely performance of proper repair and rehabilitation. The need for a timely assessment of the structural integrity and stability of dams is indicated with using modern instrumental monitoring systems of their technical condition.
\end{abstract}

Keywords: Dam safety, reservoir, risk of accidents, potential energy, ecology

Введение. Первое место среди природных богатств Грузии занимают гидроэнергетические ресурсы. На территории Грузии зафиксировано 26060 рек, изучено 319 рек для определения целесообразности развития энергетики, с потенциальной (теоретической) суммарной мощностью 15,63 млн. кВт [1, с. 85], среднегодовой выработкой - 137 млрд кВт·ч [1, с. 85]. А технический гидроэнергетический потенциал рек Грузии оценивается в 80-85 млрд кВт ч $[1$, с. 85].

В настоящее время в Грузии действует 97 гидроэлектростанций общей мощностью 3227,81 МВт [2]. Из них 72 - малые гидроэлектростанции (установленной мощностью до $13 \mathrm{MBT}$ ), общей мощностью 259,79 МВт [2]. По данным на 2020 год, существующие гидроэлектростанции в Грузии выработали 8,248 млрд кВт · ч электроэнергии [2], что составляет более $70 \%$ от производства электроэнергии в стране.

Цель работы. Целью работы является разработка методики определения и оценки риска возможных аварий плотин на основе реальных параметров водохранилищ Грузии. Имея это в виду, можно ранжировать гидроэлектростанции и определять периодичность технических осмотров на них.

В зону воздействия гидроэнергетических объектов входят: зона гидроэлектростанции с водохранилищем и окружающей его территорией по всему периметру затопления, а также нижний бьеф, где проявляется влияние водоема на ландшафт, гидрологию, гидрогеологию, геодинамические процессы, климат и т.д. Приоритеты человеческой деятельности в этой области также в некоторой степени меняются.

Гидротехнические сооружения энергообъектов Грузии, за некоторыми исключениями, относятся к категории старых. В результате длительной эксплуатации ухудшается техническое состояние гидроузлов, идет их физический и моральный износ, развиваются процессы фильтрации, размыва береговой полосы, активизируются оползневые процессы в породах, окружающих объект. В то же время ужесточается отношение населения к проектированию и безопасной эксплуатации гидротехнических сооружений, особенно плотин и водохранилищ, в 
соответствии с современными экологическими требованиями. Это делает очень важным изучение безопасности плотин гидроэлектростанций.

Распределение стока грузинских рек, характеризуется резко выраженной сезонностью, и их оптимальное энергетическое использование в годовом разрезе возможно только за счет строительства регулирующих водохранилищ. Поскольку этот процесс сталкивается с экологическими трудностями, основное внимание в настоящее время уделяется строительству гидроэлектростанций малой мощности, работающих на естественном стоке, а также малых ГЭС с водохранилищами небольшого объема.

Из-за гористого рельефа и небольшого неиспользуемого земельного фонда Грузии значительная часть водохранилищ страны расположена в горных районах и характеризуется небольшой зеркальной поверхностью и значительными колебаниями уровня. Последнее приводит к переработке берегов водоема, что зависит от интенсивности сработки водохранилища с одной стороны, а с другой - от физико-механических характеристик окружающего грунтового массива (плотность, показатели прочности). Кроме того, физико-механические свойства горных пород ослабляются в результате воздействия фильтрационного потока подземных вод и атмосферных осадков. Все вышеперечисленное способствует нарушению статического равновесия базовой части склонов и становится провоцирующим фактором таких опасных явлений как: лавины, оползни, обвалы. Кроме того, Грузия находится в зоне активного сейсмического воздействия, что еще больше увеличивает вероятность оползней. Оползень обрушившийся в водохранилище снижает его регулирующую способность, а также может вызвать перелив массы воды через плотину и крупномасштабную катастрофу в нижнем бьефе реки.

Методы исследования. Из вышесказанного ясно, что система «водоподпорное сооружение -водохранилище» несет в себе высокую степень риска с точки зрения потери жизни и здоровья людей, а также разрушения или серьезного ущерба их собственности, а также разрушительного воздействия на окружающую среду. С другой стороны, нет полной гарантии, что эти риски не материализуются с их катастрофическими последствиями.

Одно из важнейших мест в списке техногенных катастроф с их негативными последствиями - волна прорыва или затопления от перелива водных масс через плотины, дамбы, шлюзы в нижний бьеф, следствие -разрушение промышленных, сельскохозяйственных объектов и человеческие жертвы. Волна прорыва может оказать существенное негативное влияние на окружающую среду. В частности, может изменить ландшафт, нанести ущерб флоре и фауне, спровоцировать оползни, переработать берега рек, промыть дно русла на большие расстояния и т.д.

Из вышесказанного видно, что с учетом негативных последствий возможных аварий безопасная эксплуатация плотин водохранилищ имеет большое социально-экономическое и экологическое значение, что ставит на повестку дня задачу количественной оценки возможного воздействия волны прорыва.

Объем водохранилища и высота плотины являются характеристиками, которые в значительной степени определяют параметры волны прорыва в результате возможной аварии плотины и масштаб катастрофы, вызванной ее воздействием. Чтобы оценить потенциальный риск, связанный с аварией на плотине, будет правильным определить способность накопленной в водохранилище воды попадать в нижний бьеф. Учитывая, что при прорыве плотины как правило учитывается только отток воды, аккумулированной в полезном объеме водохранилища, в нижний бьеф, это можно выразить как [3, с. 152]:

$$
E=\gamma \cdot W_{\text {пол.. }} \cdot H
$$

где: $\quad E$ потенциальная энергия водной массы, Дж.;

1 тонна ТНТ(тринитротоуол) $=4,184 \cdot 10^{9}$ Дж.;

$\gamma=9810$ н / м ${ }^{3}$ - удельный вес воды;

$W_{\text {пол. }}-$ Полезная емкость резервуара, м $^{3}$;

$H$ - Расстояние по вертикали от центра тяжести водохранилища до дна русла реки в створе плотины, м.

Результаты исследования. Расчеты для гидроузлов водохранилищ Грузии проводились по предложенной формуле, результаты которых представлены в таблице 1.

В столбцах 6 и 7 таблицы 1 приведена потенциальная энергия воды, накопленная в водохранилище в килотоннах и в эквиваленте энергии, выделяющейся при взрыве 
тринитротоуола, что позволяет четко понять опасность, которая может возникнуть в случае прорыва плотины, тем самым подчеркивая необходимость обеспечения высокой степени безопасности водоподпорного сооружения.

По данным Международной комиссии по высоким плотинам (ICOLD) [4], 300 из 36000 плотин в мире разрушились. Значительная часть из них отмечена катастрофическими затоплениями (наводнениями). Часто это было связано с неполнотой проектной документации и неправильной работой эксплуатационных служб. В результате чего во время паводков не удается вовремя открыть основные затворы (или из-за их отказа), и вода сбрасывается за счет перелива через плотины, что сопровождается разрушением конструкции. Перелив воды через плотины также может быть связан с неисправностями гидромеханического оборудования плотины, по техническим причинам из-за нечастого использования, отсутствия профилактических работ, отсутствия периодических проверок их эксплуатационной надежности, а также отключений электроэнергии.

Имея дело с катастрофическими затоплениями в нижнем бьефе, следует учитывать вопрос устойчивости уклона русла под влиянием вымывания их основания, что может спровоцировать оползень и, как следствие, затопить территорию до новых границ (обычно более обширных).

Таблица 1.

\begin{tabular}{|c|c|c|c|c|c|c|}
\hline $\begin{array}{c}\text { № } \\
\text { п.п }\end{array}$ & $\begin{array}{c}\text { Название } \\
\text { гидроузла }\end{array}$ & $\begin{array}{c}\text { Полезный } \\
\text { объем } \\
\text { водохранилища } \\
W_{\text {пол.. }}, \text { млн. } \mathrm{M}^{3}\end{array}$ & $\begin{array}{c}\text { Глубина } \\
\text { сработки, м }\end{array}$ & $\begin{array}{c}\mathrm{H}, \mathrm{m} \\
\mathrm{E}, \\
\times 0^{13}, \\
\text { Дж }\end{array}$ & $\begin{array}{c}\mathrm{E}, \\
\text { кТн } \\
\text { ТNT }\end{array}$ \\
\hline 1 & 2 & 3 & 4 & 5 & 6 & 7 \\
\hline 1 & Енгури ГЭС & 676 & 70 & 236,5 & 156,8 & 375 \\
\hline 2 & Жинвали ГЭС & 370 & 40 & 82 & 30,8 & 74 \\
\hline 3 & Сиони ГЭС & 300 & 54 & 56 & 16,5 & 39 \\
\hline 4 & Храми ГЭС-1 & 292 & 14,5 & 25,5 & 7,3 & 17 \\
\hline 5 & Варднили ГЭС-1 & 37 & 3,55 & 53 & 1,9 & 4,5 \\
\hline 6 & Шаори ГЭС & 85 & 8 & 7,5 & 0,63 & 1,5 \\
\hline 7 & Дзеврула ГЭС & 87 & 7,5 & 32 & 2,7 & 6,5 \\
\hline 8 & Гумати ГЭС-1 & 13 & 4,0 & 50 & 0,64 & 0,25 \\
\hline 9 & Ладжанури ГЭС & 18 & 16,0 & 61 & 1,1 & 2,6 \\
\hline 10 & Варцихе ГЭС-1 & 2,6 & 0,5 & 10 & 0,33 & 0,07 \\
\hline 11 & ЗАГЭС & 3 & 1,5 & 25 & 0,07 & 0,17 \\
\hline
\end{tabular}

Возможен также прорыв дамб, образовавшихся в результате оползня, вызывающий также прорывную волну со всеми негативными последствиями.

Одной из причин возникновения нештатной ситуации на ГЭС - несвоевременное проведение надлежащего ремонта, реабилитации. Также следует отметить необходимость своевременной оценки структурной целостности и устойчивости дамб обвалования (например, Маднеули, Ткибульское водохранилище) и их влияния на качество воды с учетом агрессивности материала отходов.

В случае каскада гидроэнергетических объектов необходимо учитывать интенсивность катастрофических сбросов с верхних объектов на расположенные ниже объекты и принимать меры по трансформации избыточного стока и безопасному отведению его в нижнем бьефе. Этот вопрос приобретает особую важность при размещении каскадных объектов в разных странах. В этом случае условия безопасности и воздействия объекта на окружающую среду должны соблюдаться на основании соглашения между государствами.

В последнее время вопросам безопасности плотин и связанных с этим природоохранным мероприятиям уделяется в республике все большее внимание. Все больше плотин оснащаются современными системами мониторинга за техническим состоянием плотин и других гидросооружений (Енгури ГЭС, Жинвали ГЭС, Варднили ГЭС-1, Сиони ГЭС, плотины мелиоративного назначения - Алгети и Нареквави). Системы раннего оповещения 
внедряются как на объектах энергетики (Жинвали ГЭС), так и на важных объектах инфраструктуры (оползневой участок дороги Цхнети-Бетания, ледник Девдораки вблизи Военно-Грузинской дороги), для предотвращения либо сведения к минимуму риска как экономического ущерба, так и человеческих жертв.

\section{Выводы.}

1. Разработана методика определения и оценки риска их возможных аварий на основе реальных параметров водохранилищ Грузии.

2. Согласно предложенной методике, можно ранжировать объекты гидроэнергетики и определять периодичность их проверок с целью снижения риска аварий и связанных с ними негативных воздействий на окружающую среду.

3. Обсуждаются другие аспекты безопасности гидротехнических сооружений и связанных с ними экологических проблем.

\section{ЛИТЕРАТУРА}

1. Сванидзе Г.Г., Гагуа В.П., Сухишвили Э.В. Возобновляемые энергоресурсы Грузии: Гелио-, ветрои гидроэнерг. Ресурсы. - Л.: Гидрометеоиздат. - 1987. - 173 с.

2. ELECTRICITY MARKET OPERATOR, https://esco.ge/.

3. Оценка аварийности водохранилищных гидроузлов Грузии. // Гидротехническое строительство. 2020. - № 2. C. 148-154.

4. International Commission of Large Dam. Dam Safety. Retrieved from http://www.cawaterinfo.net/int_org/icold/dam_safety.htm. 